\title{
O papel do imaginário na construção da identidade
}

Consuelo Ivo

Jornalista, especialista em Gestão de Processos Comunicacionais, editora executiva da revista Comunicação \& Educação.

E-mail: consuelo.ivo@terra.com.br

Los hombres y lãs mujeres hacen su própria historia y lo primero que hacen es su lenguage y, en seguida, basados en el lenguagje, sus mitos,

y luego sus obras de arte, sus costumbres, leys, maneras de comer, modas, organizaciones políticas, códigos sexuales, deportes, sistemas educativos, todo ello, dice Vico, en flujo perpetuo, todo ello siendo siempre.

Carlos Fuentes ${ }^{1}$

As ciências sociais estabeleceram o campo da comunicação como o espaço no qual se verifica a construção dos sentidos e dos valores que, na vida cotidiana, estruturam o vivido e aquilo que está por viver. É nesse espaço que se produz a consciência individual e coletiva. Com base nessa premissa, encaminhei meu estudo sobre a cidade de Guarulhos, em São Paulo, visando à possibilidade de nela intervir, para auxiliar na solução da crise de identidade pela qual passa nestes tempos de globalização.

A seguir, passo a relatar o desenvolvimento da pesquisa e do projeto de gestão da comunicação que apresentei ao Arquivo Histórico de Guarulhos, órgão do núcleo do patrimônio cultural do Departamento de Atividades Culturais da Secretaria de Cultura, para a obtenção do título de especialista em Gestão da Comunicação. Um novo enfoque sobre o imaginário na construção

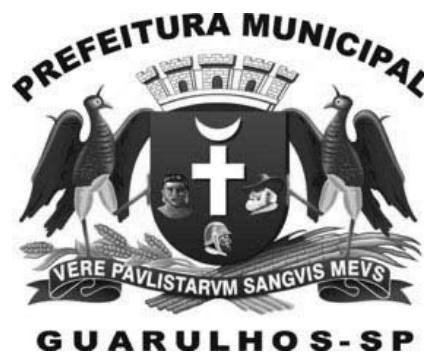

Restituído às idéias originais do pintor Wasth Rodrigues, desenhista do primeiro brasão proposto por Afonso D’Escragnole Taunay, o símbolo municipal traz as cabeças de um índio, um português e um bandeirante e representam a fundação da cidade. da identidade é a proposta desse trabalho. A partir do resgate da figura dos Índio Guaru, este projeto sugere uma articulação de elementos num estudo voltado para a valorização do mito fundador da cidade.

\section{GUARULHOS, CIDADE SÍMBOLO}

Uma das maiores cidades do estado de São Paulo, com mais de um milhão de habitantes, um dos maiores parques industriais do país, mais de 330 núcleos de favelas e $20 \%$ da população abaixo da linha da miséria. Esta é Guarulhos, localizada a $25 \mathrm{~km}$

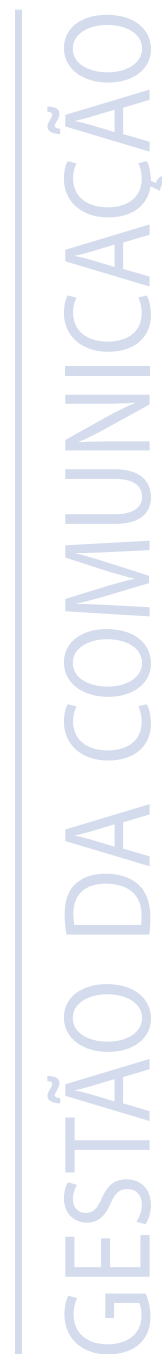

1. FUENTES, Carlos. Valiente mundo nuevo (Valente mundo novo). México: Fondo de Cultura Econômica, 1992. p. 32. 
2. IBGE. Dados preliminares CENSO 2000.

3. Disponível em: <http:// www.stm.sp.gov.br/rmsp. $\mathrm{htm}>$. Acesso em: 10 maio 2004, 22h.

4. Disponível em: <http:// www.stm.sp.gov.br/rmsp. $\mathrm{htm}>$. Acesso em: 10 maio 2004, 22h10m30.

5. CASTELLS, Manuel. A sociedade em rede. 7 . ed. São Paulo: Paz e Terra, 2003. v. 1, p. 467.

6. Ibid., p. 490.

7. PREFEITURA MUNICIPAL. Plano Diretor de Guarulhos: leitura técnica e comunitária. Secretaria de Planejamento, 2003. (Versão preliminar). Os desafios da cidade que herdamos. In: I CONFERÊNCIA DAS CIDADES: GUARULHOS PLANEJANDO O FUTURO, 2003.

8. ABREU, R. A. et al. Tendências recentes de expansão metropolitana e intramunicipal: o papel da migração no caso do Município de GuarulhosSP. Trabalho apresentado no XIII Encontro Nacional da ABEP, 4 a 8 nov. 2002, Ouro Preto-MG. de São Paulo, o retrato do potencial de crescimento econômico que não acompanhou os desafios sociais.

Para os guarulhenses, o título de Cidade Símbolo, recebido no quarto centenário de fundação, em 1960, é motivo de piada: "símbolo do abandono", "símbolo da corrupção" e outros qualificativos nada condizentes com a homenagem. Este é um dos inúmeros exemplos que reunimos na pesquisa sobre a cidade de Guarulhos e sua dificuldade histórica de constituir uma identidade.

O problema ganhou a atenção do Arquivo Histórico, após ter iniciado suas atividades no final da década de 1990. Um dos propósitos principais era evidenciar a necessidade de constituir uma identidade histórica para o município. Desde essa época, o esforço tem ocorrido no sentido de construir formas de resgate, preservação e divulgação do Patrimônio Cultural e Histórico-Social. Para alcançar seus objetivos, o Arquivo tem utilizado a comunicação como veículo de construção do imaginário local, mas as ações ficaram restritas à edição de uma coletânea de postais da história recente e alguns banners de divulgação institucional. $\mathrm{O}$ motivo é a falta de verbas, necessidade de institucionalização do órgão e descontinuidade das ações de política cultural da cidade.

\section{O GLOBAL E O LOCAL: OS IMPACTOS DA MODERNIDADE}

A cidade de Guarulhos é um dos 39 municípios que compõem a Região Metropolitana de São Paulo - RMSP, e ocupa, no estado, o segundo lugar em população, com 1.071.299 habitantes. É a maior cidade não-capital do país e o $13^{\circ}$ município mais populoso do Brasil $^{2}$. Com a criação da região metropolitana, em 1969, toda circunvizinhança teve sua vida alterada, com mudanças que afetaram a vida de uma população ${ }^{3}$ estimada em 16,3 milhões de habitantes, cifra superior à de diversas nações. A RMSP, incluindo Guarulhos, é um dos maiores aglomerados urbanos do mundo e sua área quadrada corresponde a menos de um milésimo da superfície brasileira e a menos de $4 \%$ do território do estado ${ }^{4}$. Ainda que pequena em relação ao território brasileiro e estadual, a dimensão da RMSP é muito próxima à de alguns países.

Para Castells ${ }^{5}$, a nova economia global e a sociedade informacional emergente de fato apresentam uma forma espacial que se desenvolveu em vários contextos geográficos e sociais, resultando naquilo que se convencionou denominar "megacidades"6. São aglomerações enormes de seres humanos, segundo classificação da Organização das Nações Unidas - ONU, com mais de dez milhões de pessoas em 1992.

O alto adensamento populacional de Guarulhos é explicado pelo ritmo de crescimento durante o século XX, especialmente na sua segunda metade. Nos últimos 50 anos, a cidade cresceu pela migração de pessoas vindas da capital, do interior do estado e de outros estados brasileiros ${ }^{7}$. As atuais características socioeconômicas da população são, em grande parte, reflexos dos processos migratórios intensos que ocorreram nas décadas recentes. Os maiores contingentes de migrantes de Guarulhos vieram das regiões Sudeste e Nordeste ${ }^{8}$, e 
apontam um aumento das taxas de crescimento populacional nos bairros periféricos, que crescem em função do aumento da demanda por áreas em que o preço da terra seja mais acessível ou da ocupação irregular.

Ao analisar como a Revolução Francesa transformou súditos em cidadãos, Immanuel Wallerstein mostra como transformou o conceito de cidadania após os Estados tornarem-se teoricamente, e até certo ponto na prática, responsáveis por um grande grupo de pessoas com reivindicações políticas constituídas: "Se existem cidadãos, existirão igualmente não-cidadãos" ${ }^{9}$.

[...] Foi o conceito de cidadão que mudou o significado do termo migrante. Uma pessoa que deixa a área rural ou uma cidade pequena e vai para uma cidade grande a 50 quilômetros de distância pode estar passando por uma transformação social tão grande quanto alguém que se muda para uma cidade grande a cinco mil quilômetros de distância ${ }^{10}$.

Dividida entre os que nasceram na cidade e os forasteiros, Guarulhos obedece à lógica do mercado instaurado pelo neoliberalismo. A exemplo do que ocorre nos grandes centros urbanos mundiais, tem sua população carente estigmatizada, restando-lhe como única saída manter a todo custo uma identificação com a terra natal, sem jamais estabelecer identidade e vínculo afetivo com o lugar onde mora e trabalha.

\section{AEROPORTO INTERNACIONAL: PERTO DOS OLHOS E LONGE DO CORAÇÃO}

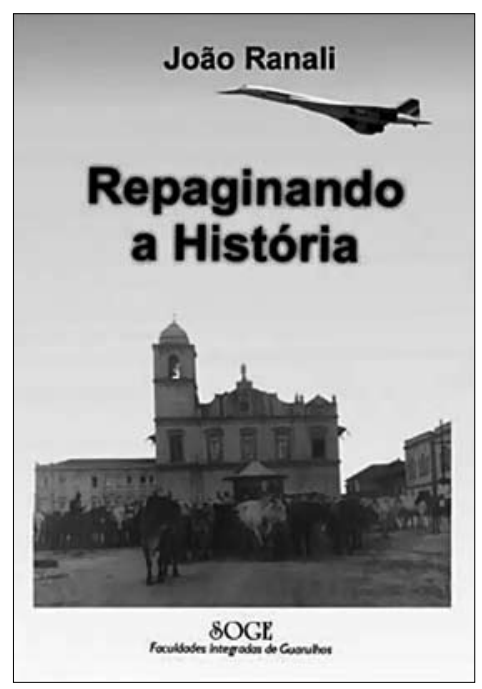

Na capa do livro de João Ranali os elementos constituídos no tempo e no espaço polarizam as concepções do lugar.
A dinâmica de crescimento da cidade industrializada e globalizada introduziu em Guarulhos as vias de transportes necessárias ao desenvolvimento e distribuição capitalistas para atender a demanda econômica da capital, instalando em seu território o maior e mais importante aeroporto internacional do país. Com o paradigma da globalização, passou a orientar a política de desenvolvimento do município, e vem tentando se afirmar como cidade aeroportuária e manter sua posição de centro de um dos maiores entroncamentos logísticos do país. Em 1985, a inauguração do aeroporto internacional de Cumbica ligou Guarulhos a 202 cidades em 63 países dos cinco continentes, embarcando e desembarcando passageiros de 215 destinos diferentes, dos quais 135 internacionais e 80 nacionais.

Ao caracterizar a situação de supermodernidade, Marc Augè elege três figuras do excesso que afetaram as grandes categorias por meio das quais os homens pensam sua identidade e suas relações recíprocas, sendo que uma
9. WALLERSTEIN, Immanuel. Como concebemos do mundo o fim: ciência social para o século XXI. Rio de Janeiro: Revan, 2002. p. 144.

10. Ibid., p. 146. 
11. AUGÈ, Marc. Não-lugares: introdução a uma antropologia da supermodernidade. Campinas: Papirus, 2003. p. 36.

12. Ibid., p. 95.

13. Disponível em: <http:// www.guarulhos.sp.gov. br>. Acesso em: 13 abr. 2004, $14 \mathrm{~h} 48$.

14. RANALI, João. Repaginando a história. São Paulo: SOGE, 2002. 343 p.

15. PREZIA, Benedito. Os indígenas do Planalto Paulista: nas crônicas quinhentistas e seiscentistas. São Paulo: Humanitas, 2000. p. 63. delas - a superabundância espacial - se expressa nas mudanças de escala, na multiplicação de referências energéticas e imaginárias e nas espetaculares acelerações dos meios de transporte, resultando em consideráveis modificações físicas, concentrações urbanas, transferências de população e multiplicação a que chamou de não-lugares: “[...] são tanto as instalações necessárias à circulação das pessoas e bens (vias expressas, trevos rodoviários, aeroportos) quanto os próprios meios de transporte ou os grandes centros comerciais..."11.

A presença do aeroporto internacional é absorvida de forma antagônica pelos diversos extratos da população de Guarulhos. Para parte dela não passa de um mito, uma vez que nunca freqüentou o local nem pode usufruir de seus serviços. Para grupos políticos, o aeroporto suscita calorosos debates em torno de sua ampliação, mesmo que sob a possibilidade de desapropriação de inúmeros bairros para a instalação do terceiro terminal. Bem ao lado do aeroporto, separado apenas por uma cerca-viva, o bairro do Bananal abriga um grande número de famílias pobres cujo destino está diretamente ligado à expansão do aeroporto. Para o viajante que utiliza o aeroporto internacional de Cumbica, essas pessoas estão invisíveis. Ele é portador instantaneamente daquilo que Augè chama de desindentificação, afastado pelo seu ambiente do momento das preocupações que o cercavam de véspera. "O espaço do não-lugar não cria nem identidade singular, nem relação, mas sim solidão e similitude"12.

\section{O ÍNDIO GUARU}

No processo de resgate da memória iniciado pelo Arquivo Histórico, foram evidenciadas questões polêmicas sobre os registros dados como históricos, que envolvem a procedência e o etnônimo dos índios aldeados no território onde hoje é a cidade e sobre quem teria sido o fundador. Concorrem para o feito o nome de outros jesuítas, além de Manuel de Paiva, referência mais utilizada pela municipalidade nos relatos oficiais, como se pode verificar nos sites da prefeitura ${ }^{13}$, Câmara Municipal e do Governo Estadual, sempre com base nas obras de João Ranali. Apesar de prestigiado na cidade como o primeiro historiador do município, tendo escrito, em 1945, A história de Guarulhos, os historiadores locais comentam com reservas suas obras, apontando falhas nas referências bibliográficas, entre outras críticas. João Ranali, delegado aposentado, não mostra incômodo com o descrédito e sua obra Repaginando a história ${ }^{14}$, publicada em 2002, por ocasião das comemorações do 442 a aniversário de fundação da cidade, reitera a maior parte das informações que reuniu nestes cerca de 60 anos na lida de historiador local.

Nas pesquisas que tem realizado sobre os indígenas no Planalto Paulista ${ }^{15}$, o historiador Benedito Prezia atribui o feito ao padre Manuel Viegas. As peculiaridades do grupo indígena aldeado em Guarulhos teriam sido responsáveis pela sua rápida extinção, motivo pelo qual seria tão difícil reunir informações que ajudassem a desfazer os equívocos a seu respeito:

A presença de populações tupis no litoral foi tão acentuada no século XVI que até há pouco tempo a cultura brasileira indígena era sinônimo de tupi, ficando 
os demais povos e culturas relegados a segundo plano, quando não omitidos. Devido a isso muitos equívocos se cometeram, como foi o esquecimento de grupos numericamente menores, como os maromomi/guarulho ${ }^{16}$.

Para a população, de um modo geral, a polêmica não existe. Uma pequena parte dela conhece as origens do município e está acostumada com a história de que a cidade teria sua origem nos índios guarus, representados nos símbolos municipais (brasão, bandeira e hino), ao lado de um português e de um bandeirante. O nome guaru também é emprestado a vários estabelecimentos comerciais da cidade como restaurantes, jornais, padarias, casas de material de construção, concessionárias, além do grande número de ruas com nomes indígenas.

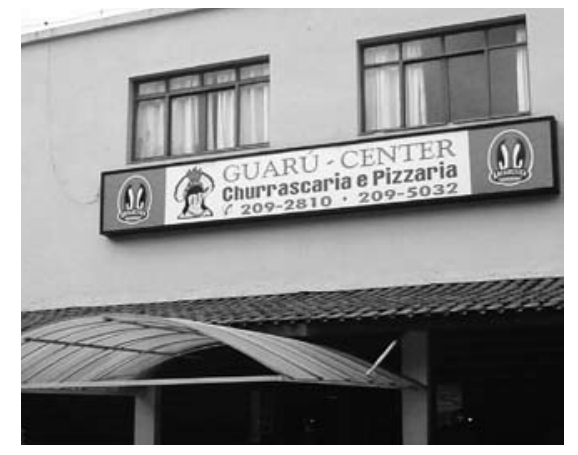

Não é raro encontrar na cidade estabelecimentos identificados com a figura do índio guaru.

\section{O PROBLEMA}

No decorrer deste trabalho, foram analisadas questões sobre o processo sociohistórico de Guarulhos que pudessem nos levar a compreender os motivos da ausência de uma identidade local.

A oportunidade de contribuir para a solução da crise de identidade pela qual a cidade passa surgiu das impressões colhidas no exercício de assessoria de imprensa e coordenadoria de comunicação num tradicional centro universitário de Guarulhos. Constatei que havia um sentimento de inferioridade entre os guarulhenses, moradores da cidade ou não. $\mathrm{O}$ incômodo reflete-se na idéia de que o município não tem vida própria e, apesar da proximidade com a capital, mantém os ares de acanhamento típico das cidades do interior. $\mathrm{O}$ ressentimento da população também é expresso pelas contradições de sua economia, riqueza alardeada e pouco dividida. Outros segmentos da sociedade também já demonstraram que a falta de identidade é um problema que transpassa todos os níveis da cidade. Uma pesquisa elaborada pela Associação Comercial e Industrial de Guarulhos - ACIG, em parceria com o SEBRAE-SP e a Universidade Guarulhos em 1998, por ocasião da instalação do Internacional Shopping, primeiro empreendimento na cidade na área de serviços e lazer de grande porte, concluiu que a cidade necessitava voltar-se para o mundo, e as barreiras a serem superadas apontavam em primeiro lugar a cisão da identidade, além de ausência de lideranças locais, falta de iniciativas municipais, desqualificação da mão-de-obra, precários serviços públicos, baixa qualidade de vida, alto grau de favelização, desemprego, trânsito caótico, necessidades de novas vias de acesso e violência urbana.

Como vimos, a história de Guarulhos tem sido construída por uma população em sua maioria composta de migrantes. Deslocados de sua terra natal, reconstroem suas vidas em meio ao caos da cidade que não os reconhece como cidadãos. São eles importantes atores/receptores invisíveis às pesquisas de mercado. Seus prazeres são tidos como alienação e seu cotidiano é menosprezado, 
quando poderiam oferecer riquíssimas pistas de suas práticas e preferências de consumo, conforme nos aponta Barbero: "A cotidianidade que não está inscrita imediata e diretamente na estrutura produtiva é despolitizada e assim considerada irrelevante, insignificante" ${ }^{17}$.

É preciso esclarecer que a proposta do tema do índio guaru é apenas um argumento para a constituição da identidade, não a identidade propriamente dita. Em Tiempo y espacio de la novela, Carlos Fuentes conta como Giambattista Vico opunha-se aos critérios do racionalismo, em particular a distinção cartesiana das idéias "claras e distintas", objetivas e científicas, como o único caminho para conhecer a verdade. Segundo ele, essas idéias cartesianas existem com independência de seu progresso histórico e de seu contexto cultural e são a base de uma conhecimento verificável: "[...] uma ciência de la natureza humana liberada, al fin, del mito, la superstición, la fábula y otros cocidos próximos a la hechicería"18. Segundo Fuentes, para Vico a natureza humana é uma realidade variada, historicamente ligada, eternamente em transformação, móvel, portando, porém, a bagagem das criações culturais da própria história.

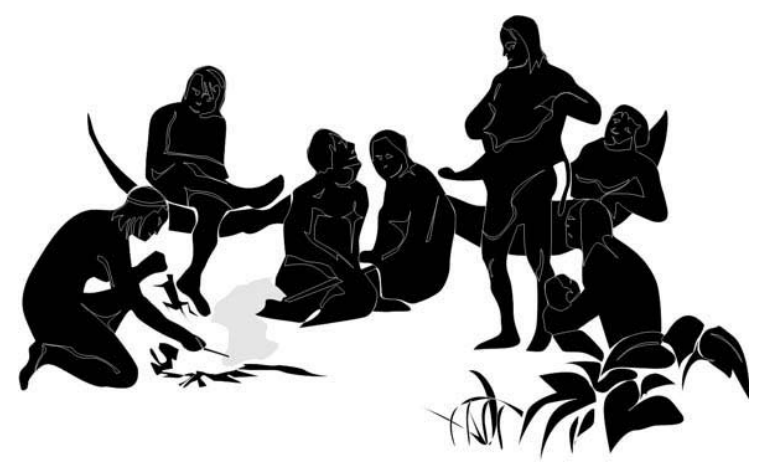

Interferência em gravura de Rugendas (Grupo Puri, 1875), pelo artista plástico Marco Noronha, especialmente para este trabalho.

Os índios aldeados no território que originou Guarulhos são protagonistas de uma história que ainda está por ser contada. Abre-se com isso uma maravilhosa oportunidade de colaborar para o esforço que se inicia em algumas frentes no país de uma reflexão sobre a forma pela qual o imaginário das populações da cidade ajuda a formar uma visão equivocada e distorcida sobre os grupos indígenas brasileiros e suas representações em nossa sociedade.

Estimula-nos, ainda, que na esfera cultural contemporânea a temática abordada em recentes exposições tem exultado os organizadores com surpreendentes recordes de público em suas mostras, como a ocorrida em 2003 na Pinacoteca do Estado de São Paulo quando da apresentação do

77. MARTÍN-BARBERO Jesús. Dos meios às mediações: comunicação, cultura e hegemonia. 2 . ed. Rio de Janeiro: UFRJ, 2003. p. 301.

18. FUENTES, Carlos, op. cit., p. 30.

19. PINACOTECA DO ESTADO. Albert Eckhout volta ao Brasil: 1644 2003. 1 Folder. São Paulo, 2003. conjunto pictórico de Albert Eckhout, sendo um dos seis ambientes da Mostra o registro da presença holandesa no Brasil seiscentista. A mostra ainda contemplou em seus espaços os retratos dos habitantes do Brasil, "estudados como representações simbólicas da diversidade étnica e trocas multiculturais que se estabeleceram em terras brasileiras", ainda assinalando o panfleto "a manifesta esperança de que o evento permitirá uma avaliação, sob nova ótica, desse singular capítulo do período colonial de nosso país, revisando-o, não como pálida lembrança, mas como herança viva que faz refletir sobre o Brasil"19. 


\section{A PESOUISA: METODOLOGIA}

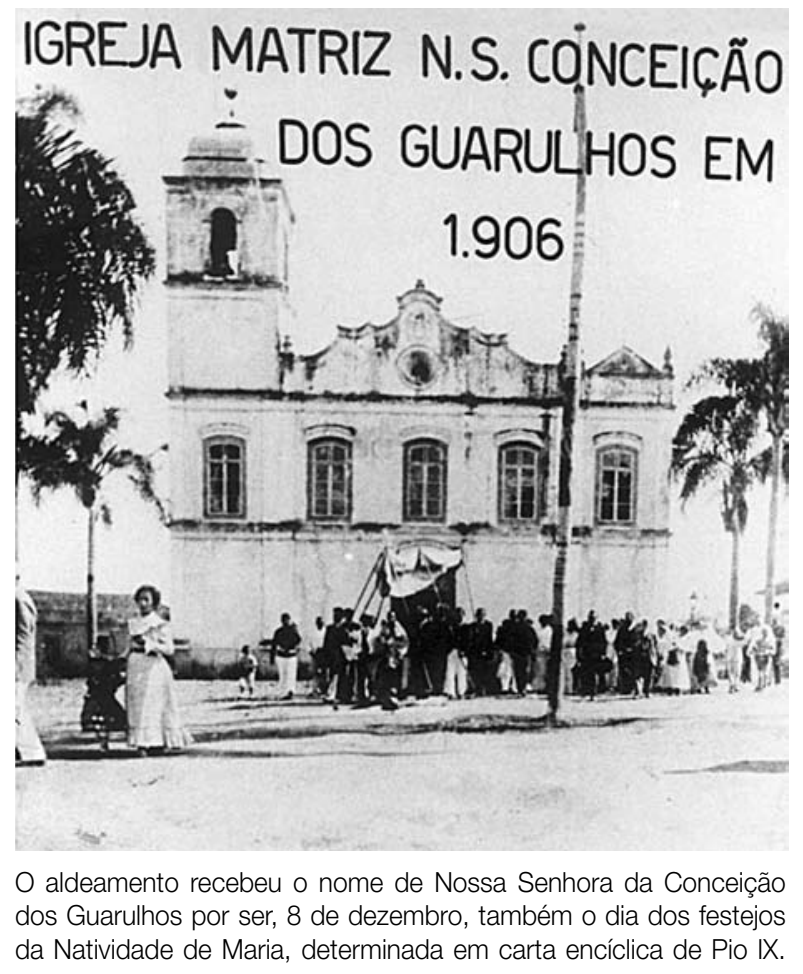

Para situar o problema de pesquisa e estabelecer o vínculo entre o objeto empírico e o objeto teórico dentro do cenário atual dos meios de comunicação de massa, o gestor de comunicação vai apoiar-se naqueles estudos voltados para um melhor entendimento das características culturais de comunidades, com vistas ao desenvolvimento local delas. Pretende-se, com a análise, confirmar que as indústrias culturais e os multimídias estabelecem uma nova relação estética do homem tanto com a realidade quanto, sobretudo, com as relações do imaginário humano e a cultura. Para muitos guarulhenses o retorno às origens não vai além do passado remoto, como a chegada de imigrantes europeus na cidade, o que contribui para um apagamento do mito fundador e todas as questões relacionadas às mestiçagens, como tão bem identificado nos estudos sobre a identidade dos povos latino-americanos.

Partimos do pressuposto de que, a despeito da polêmica sobre os dados históricos da fundação, o índio guaru pode ser um elemento e referência para a constituição da identidade da população da cidade. Essa identidade pode ser constituída e estimulada pela comunicação, valorizando seus mitos, sua língua e sua memória. Isso requer a participação da população na construção de uma identidade histórica e simbólica. Falar da identidade é buscar nas raízes o sentido do presente. Assim é que a nossa pesquisa procurou identificar:

1. Existe o índio guaru na memória do cidadão?

2. O que ele significa?

Entre os objetivos principais da pesquisa realizada, destacamos o interesse em investigar:

1. O índio guaru pode ser um elemento e referência para a constituição da identidade da população da cidade?

2. Essa identidade pode ser constituída e estimulada pela comunicação, valorizando seus mitos, sua língua e sua memória?

3. Como se dá a participação da população na construção dessa identidade histórica e simbólica? 
À época da realização da presente pesquisa foram ouvidas 60 pessoas, de ambos os sexos, em áreas públicas do município de Guarulhos. Decidimos realizar a pesquisa com uma amostra em áreas freqüentadas pela maior parte dos entrevistados, com um universo diversificado de ocupação econômica, níveis escolar, social e cultural. Foram ouvidas pessoas de várias idades, entre elas donas de casa, servidores municipais, ambulantes, estudantes, comerciários, aposentados, prestadores de serviços, policiais militares, entre outros.

\section{INSTRUMENTOS}

Para averiguar as indagações do problema de pesquisa utilizamos questionário, entrevistas e uma pesquisa bibliográfica. Procedemos a coleta de dados através de questionário, dentre as técnicas de coleta existentes, o qual, constituído de cinco perguntas abertas, foi preenchido pela pesquisadora, uma vez que se aplicou em áreas públicas abertas, em abordagem direta dos pedestres. Nesse contato, também foi possível aplicar uma observação indireta, pois a maior parte das pessoas discorreu além das questões apresentadas, oferecendo um universo rico de percepções de seu imaginário. Pudemos, assim, levantar tanto dados quantitativos como qualitativos.

\section{PESQUISA DE CAMPO MODELO DO QUESTIONÁRIO}

1. Você tem orgulho de descender do índio guaru? Ou possivelmente de outra nação indígena brasileira?

2. Por quê?

3. O que você sabe sobre ele?

4. O que ele tem de bom para a cidade/ou para você?

5. O que há de ruim?

Pergunta 1. Você tem orgulho de descender do índio guaru? Ou possivelmente de outra nação indígena brasileira?

Dos 60 entrevistados, 54 pessoas alegaram que sentiriam orgulho de descender do índio guaru ou de qualquer outra nação indígena.

\section{Pergunta 2. Por quê? (Motivos de a pessoa sentir orgulho.)}

Reunimos em quatro grupos as respostas referentes aos motivos alegados para sentir orgulho de descender do guaru ou de qualquer outra nação indígena brasileira: origem, cultura, qualidades e desinteresse. Dos 60 entrevistados, 27 pessoas deram respostas diretamente relacionadas às origens dos indígenas por serem eles os primeiros habitantes do País. Outras respostas relacionadas a esse grupo lembraram a condição humana e a igualdade, sendo três respostas diretamente ligadas à descendência do entrevistado. A cultura dos indígenas foi alegada por oito entrevistados como o motivo de orgulho. As respostas disseram respeito 
ao trabalho, artesanato, cultura, sociedade saudável e a prática do naturalismo, além do cuidado com a natureza. As qualidades dos indígenas foram lembradas por 12 das 60 pessoas entrevistadas. Nesse grupo reunimos respostas sobre a coragem, a capacidade de defesa perante os brancos, a noção de que são pessoas lutadoras, honestas e de importarem-se com seus feitos. Também foram citados por integrarem uma sociedade superior, pela sua união, simplicidade e o caráter pacífico de sua gente.

\section{Pergunta 3. O que você sabe sobre ele ou/dos índios?}

Reunimos seis grupos de categoria de respostas sobre o conhecimento dos entrevistados sobre os índios: cultura, informações escolares/estereótipos, valores, colonização/conflitos atuais e aculturamento. Os elementos da cultura indígena foram os mais lembrados por 24 das 60 pessoas entrevistadas. Foram citados a cultura de forma genérica, o artesanato, as técnicas próprias para viver/cuidar da natureza ou a sobrevivência através da pesca/caça, bem como a utilização de plantas e ervas medicinais para os cuidados com a saúde. A alimentação natural também foi mencionada.

Quanto às respostas reunidas sob a categoria escolares/estereótipos, 15 entrevistados identificaram nessa categoria os conhecimentos que têm sobre os indígenas em informações básicas da escola, outros lembraram a vida em meio à natureza. Aqui pudemos encontrar uma resposta referente ao índio guaru, como sendo "feio, gordinho e barrigudo". Uma pessoa citou a beleza da cor da pele, e surgiram respostas também sobre a inocência e "limpeza mental". Um outro grupo de respostas obtidas com relação ao conhecimento das pessoas sobre os indígenas é aquele em que foram reunidos adjetivos relativos aos valores dos indígenas, nove entre 60 respostas. Cinco pessoas disseram que sabiam que eles defendem suas terras e que são corajosos, que são unidos e que trabalham para o bem comum. Também foi citado que os índios são rigorosos e honestos, e que são pessoas como qualquer outra. Outras oito pessoas ofereceram respostas que organizamos no grupo colonização/conflitos atuais: revelaram seus conhecimentos quanto aos índios serem os primeiros habitantes e terem colaborado para a formação do país. Nesse grupo as pessoas disseram estar cientes dos massacres e da luta pelas suas terras e também foram aludidos a agressividade e o sofrimento causado pela colonização. No grupo denominado aculturamento, reunimos as respostas referentes ao conhecimento sobre os índios estarem perdendo sua cultura e de que estão modernos e tecnológicos.

\section{Pergunta 4. O que ele tem de bom para a cidade/ou para você?}

Reunimos as respostas sobre o conhecimento dos entrevistados a respeitos dos índios em quatro categorias: cultura/organização social, valores, domínio do meio ambiente e nenhuma contribuição. Nas contribuições relatadas como valores, juntaram-se 25 das 60 respostas. As contribuições possíveis são referentes à união/paz, respeito/caráter/honestidade, liberdade, simplicidade, igualdade, inteligência, o saber o que se quer e o respeito pelo branco. No grupo cultura/ organização social situaram-se 17 das respostas. Foram citadas como contribuições 
possíveis o sentido de comunidade, a cultura, a arte de sobreviver/autonomia e as armas. Novamente, as questões ligadas à natureza surgem para a formação de um grupo, denominado aqui como domínio do meio ambiente. Foram 14 indicações sobre o cuidado com a natureza/preservação e três respostas sobre a utilização da medicina alternativa. Dos 60 entrevistados na pesquisa, apenas quatro disseram que o índio não teria nenhuma contribuição a dar.

\section{Pergunta 5. O que há de ruim?}

Formamos cinco grupos de categoria de respostas para verificar os traços negativos que foram citados pelos entrevistados com respeito aos índios: agressividade/vícios, cultura, o atraso e nada de ruim. No grupo agressividade/vícios, seis pessoas mencionaram a violência como um traço negativo dos indígenas, destacando que a maior parte deles identificou esses traços em função do episódio dos índios cintas largas da reserva Roosevelt, em Rondônia, e a morte de garimpeiros, amplamente divulgada pelos meios de comunicação, sendo a televisão referida como a maior fonte das informações. Apenas uma pessoa referiu-se à assimilação de vícios dos brancos, como as bebidas alcoólicas. No grupo reunido na categoria cultura, os traços negativos foram identificados em seis repostas, relacionadas com o infanticídio, a cultura propriamente dita, as interferências estéticas no corpo (furações), o aculturamento, a preguiça e a falta de uma religião. O atraso cultural foi lembrado por três pessoas, exemplificado em duas respostas sobre a ignorância e não-evolução e uma sobre a falta de acesso à tecnologia. Na categoria sociabilidade, três pessoas apontaram o egoísmo e a sisudez e uma apontou os índios como generalistas quanto ao "racismo" de que são vítimas. Uma grande maioria das respostas da amostra concentrou-se no item nada contra, totalizando 40 respostas.

\section{ANÁLISE DE DADOS}

Pudemos confirmar pela aplicação do questionário que há identificação da população com o índio guaru ou de outra nação indígena. A maior parte afirmou ter orgulho de descender dos índios guaru ou de outra nação indígena brasileira. Os motivos alegados para essa afirmação puderam ser reunidos em três grupos de respostas, predominantes e nesta ordem: a origem, a cultura e as qualidades. O que a população sabe sobre o índio guaru ou de outra nação não é específico. As generalizações resultaram em cinco grupos com as impressões mais comuns: cultura, informações escolares/estereótipos, valores, colonização/conflitos atuais e aculturamento. Houve uma grande maioria de respostas positivas sobre a contribuição que o índio poderia trazer para o pesquisado ou a cidade. Formaram três grupos de respostas mais comuns: valores/qualidades, cultura/organização social e dominio do meio ambiente. Quanto à contribuição que o índio pode oferecer de positivo a uma cidade ou para alguém, comparada ao que ele teria de negativo, verifica-se um grande número de respostas positivas sobre os valores indígenas. 


\section{A IDENTIDADE CONSTRUÍDA DE REALIDADES DIFERENTES}

A pesquisa confirmou o pressuposto deste trabalho, isto é, de que se pode constituir uma identidade para os guarulhenses utilizando o imaginário de sua população sobre o índio guaru. Mais da metade das pessoas na amostra declarou que sentiriam orgulho se descendessem do índio guaru ou de outra nação indígena. Uma grande maioria justificou para tanto as origens e a noção de serem os indígenas os primeiros habitantes do país. Apesar do pouco conhecimento que a população tem sobre o índio guaru, o que se sabe pode ser atribuído a qualquer indígena, como tem sido relatado em outras pesquisas sobre o imaginário das populações. As atribuições são em sua maioria positivas e concentram-se especialmente em valores como união, cuidados com a natureza e o meio ambiente, coragem e sentido de comunidade. A amostra demonstrou também que, apesar do conhecimento genérico, há uma noção sobre os problemas que afetam as populações indígenas na atualidade, como os conflitos em suas terras, causando a noção do surgimento de uma agressividade motivada e não espontânea. $\mathrm{O}$ estranhamento pode ser justificado por conflitar diretamente com a noção de uma sociedade unida e pacífica, um dos valores mais lembrados pela amostra na pergunta 4 .

\section{IMPRESSÕES COLHIDAS DURANTE A PESQUISA: INDÍCIOS E SINAIS}

O gestor de processos comunicacionais deve iniciar seu trabalho de intervenção configurando, teórica e empiricamente, seu objeto de interesse como um problema a ser desvendado. Citando Carlos Ginzburg, Cristina Costa lembra como devemos estar sempre atentos aos sinais que surjam, porventura, em nosso campo de interesse e de visão, "ainda que tais sinais sejam infinitesimais" ${ }^{20}$. Colhemos muitas impressões exteriores aos instrumentos de pesquisa previstos na metodologia deste trabalho. Era visível a mudança do estado de ânimo das pessoas, tanto das que participaram da amostra como das responsáveis por repartições públicas. A princípio aborrecidas com a abordagem, tornavam-se imediatamente colaborativas após mencionado o objeto da pesquisa: o índio guaru. Não raro, discursavam além do solicitado, ocorrendo demonstrações de carinho, emoção e vivo interesse pela história do índio guaru, caso a pesquisadora se dispusesse a falar mais.

\section{O PROJETO}

A despeito dos problemas verificados pela ausência de sua institucionalização e de uma política de cultura, a sorte do Arquivo Histórico de Guarulhos não é privilégio local, mas um impasse a que muitas cidades brasileiras chegaram. Nossa proposta de intervenção no Arquivo Histórico é dirigida nesse sentido.

Para Alves ${ }^{21}$, é dever do gestor reconhecer que a constituição de políticas de comunicação e cultura, em âmbitos local e regional, nos espaços público e

20. COSTA, Maria Cristina Castilho. Planejando os projetos de comunicação. In: BACCEGA, Maria Aparecida (Org.). Gestão de processos comunicacionais. São Paulo: Atlas, 2002. p. 172.

21. ALVES, Luiz Roberto. Política de formação e formação de política de gestores para a comunicação e a cultura. In: BACCEGA, Maria Aparecida (Org.). op. cit., p. 138. 


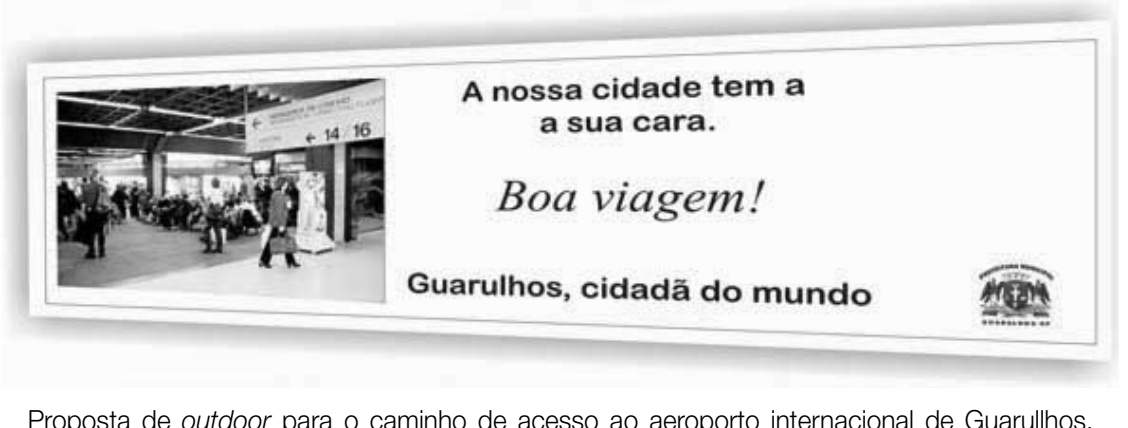

privado, deve superar em muito os modos burocrático, negociante, patrimonialista e encantado, que permeiam os projetos denominados de política cultural/comunicacional. Seu papel é checar e questionar os instrumentos metodológicos que, no interior das práticas políticas de comunicação e cultura, são tidos como indispensáveis para conectar projetos e ações, convivência espaço-temporal, movimentos culturais entre indivíduos, grupo e massa.

As mediações, as articulações culturais, foram um mapa noturno que serviu para questionar as mesmas coisas - dominação, produção e trabalho - mas a partir do outro lado: as brechas, o consumo e o prazer ${ }^{22}$.

Para o gestor de processos comunicacionais, ter clara a dimensão cultural nos modos de vida é promover, segundo Alves, mediações capazes de enriquecer os lugares da invenção, da integração política, da memória produtiva da rede de sentidos e prática de cidadania. O cotidiano é o universo da desatenção, do efêmero, das rotinas e da pressa e se constitui no espaço ideal para o controle social. Aí se pode observar o papel dos meios de comunicação de massa. Porém, dada sua condição de centro da práxis, o cotidiano é, ao mesmo tempo, o lugar das mudanças, onde primeiro se podem surpreender os novos significados e os percursos prováveis no caminho da ratificação e/ou retificação da ideologia dominante, o que exige a reflexão crítica do gestor dos processos comunicacionais. Para tanto, enfatizam-se a valorização e a preservação da identidade cultural do lugar, contemporânea e passada, enquanto contribuição para o incremento da auto-estima e a melhoria da qualidade de vida local, ao mesmo tempo que a convida a abrir-se para a diversidade e o dinamismo da humanidade e encontrar novos caminhos para o diálogo entre diferentes modos de ser, viver e pensar, amparados na experiência estética proporcionada pelos meios de comunicação de massa.

Com a pesquisa, pudemos verificar que, apesar do congelamento histórico a que foram submetidos os povos indígenas, o que ficou no imaginário nacional é superadamente mais valorativo e suas qualidades e defeitos muito mais condizentes com a realidade das classes menos favorecidas. $\mathrm{O}$ gestor deve estar preparado para não se deixar enganar pelo erro fácil da retificação da hegemonia na assimilação apressada de uma concepção ideológica que por um longo tempo manteve a questão indígena presa a um pensamento populista e romântico, que identificou o índio com esse ideário, e este, por sua vez, com o primitivo. É disso que nos fala Barbero: 
Pensar o indígena na América Latina não é propor somente a questão dos 28 milhões de índios agrupados em cerca de 400 etnias; é propor também a questão dos povos profundos, que atravessa e complexifica, mesmo nos países que não têm populações indígenas, o sentido político e cultural do popular ${ }^{23}$.

Vislumbramos assim uma comunicação que ofereça uma projeção para o Arquivo, além daqueles projetos desenvolvidos pela Secretaria de Cultura, à qual se vincula. Sugerimos quatro frentes de atuação para o estabelecimento de uma proposta de atuação de incentivo à construção de uma identidade para o município:

\section{1. Área de comunicação do Arquivo Histórico}

A atuação nessa área deve ser processual, contínua, aberta, não-burocrática e não-instrumental. Sugere-se manter um diálogo permanente com a cidade, em seus diversos setores: comunidades, órgãos públicos e setor privado (indústria e comércio e prestação de serviços). A construção de parcerias é hoje uma realidade na vida das grandes cidades e pode ser alcançada privilegiando o espaço público determinado pela necessidade da população em primeiro lugar.

\section{Identidade}

O tema do índio guaru, estabelecido positivamente como argumento para a constituição da identidade, oferece um rico contexto de abordagens. A divulgação de informações, especialmente aquela que aceita que há uma polêmica em torno dos dados históricos de sua origem, pode ocorrer de forma lúdica, educacional e artística, de modo a erigir pontes para a investigação de outros temas secundários mas igualmente importantes na construção da identidade da cidade.

\section{Formalização dos instrumentos de trabalho}

O estudo realizado pode ser um laboratório para a elaboração de uma pesquisa mais ampla na sociedade, envolvendo todos os seus segmentos. Seria de grande recurso a criação de um grupo de discussão paralelo para, desse modo, garantir que a identificação das falas nos discursos possam ser descobertas no universo da pesquisa quantitativa. Assim é que poderemos definir a utilização das inúmeras possibilidades de comunicação para o diálogo contínuo com a comunidade e seus diversos públicos. A atuação deve contemplar os relacionamentos mediados pelos veículos de comunicação (jornal, revista e internet) e pelas relações primárias (comunidade e setor privado), com a criação de publicações específicas como jornal, folder e um catálogo institucional.

\section{Atuação na área da cultura}

É na cultura que o imaginário, por meio do lazer, pode ser estimulado. A ação, envolvimento, diálogo, emoção podem ser estabelecidos na Secretaria de Cultura, nos projetos realizados e patrocinados pelo fundo de cultura municipal 
para os diversos grupos de artes cênicas e visuais, música, literatura e cultura popular que atraem públicos variados a preços populares. Nesses grupos, é possível catalisar as discussões política e ideológica para a constituição de uma identidade construída na e pela comunidade.

Resumo: A cidade de Guarulhos apresenta uma dificuldade na construção de sua identidade histórica. Um novo enfoque sobre o papel do imaginário na construção da identidade é a proposta deste trabalho. Este estudo elege o mito fundador da cidade de Guarulhos como tema para o projeto de intervenção no Arquivo Histórico, que tem procurado construir formas de resgate, preservação e divulgação da memória do município através da comunicação. A partir da análise das transformações dos processos comunicacionais da contemporaneidade, este trabalho tem como objetivo materializar a construção da identidade da cidade com uma proposta de comunicação que privilegie o cotidiano, no qual se manifestam tanto a consciência social quanto a consciência estética.

Palavras-chave: comunicação, imaginário, identidade, Guarulhos, cotidiano.
Abstract: Guarulhos city presents serious difficulties in the construction of its historical identity. A new approach on imaginary role in identity construction is proposed in this article. It chooses Guarulhos myth of foundation as project theme to Historical Archive, in order to elaborate a plan of preservation and divulgation of the historical memory of the city trough communication. After analysing changes of communicational processes of contemporaneousness, this work aims at city identity construction with a communication proposal with emphasis on quotidian based on social and esthetical consciousness.

Keywords: communication, imaginary, identity, Guarulhos city, quotidian. 